\title{
TRADISI MANOE PUCOK DALAM UPACARA PERKAWINAN DI GAMPONG GUNONG CUT KECAMATAN TANGAN-TANGAN ACEH BARAT DAYA: KAJIAN ANTROPOLOGI BUDAYA
}

\author{
Linda Wati Nur ${ }^{1}$, Teuku Kemal Fasya ${ }^{1}$ \\ 1 Program Studi Antropologi, Fakultas Ilmu Sosial dan Ilmu Politik \\ Universitas Malikussaleh
}

Korespondesi: lwatinur@gamil.compp

\begin{abstract}
Abstrak: Penelitian ini bertujuan untuk menganalisis bagaimana tradisi Manoe Pucok pada masyarakat Gampong Gunong Cut Kecamatan Tangan-Tangan Aceh Barat Daya dan untuk mengetahui seperti apa makna dari tradisi Manoe Puco kmasyarakat Gampong Gunong Cut Kecamatan Tangan-Tangan Aceh Barat Daya. Metode yang digunakan dalam penelitian ini adalah menggambarkan kajian tentang antropolog ibudaya.Sumber data dalam penelitian terdiri dari data primer dan sekunder. Teknik pengumpulan data yang digunakan adalah observasi, wawancara dan dokumentasi.Hasil penelitian menunjukkan bahwa pemahaman tradisi Manoe Pucok pada masyarakat Gampong Gunong Cut merupakan bagian yang senantiasa dilakukan dalam upacara perkawinan maupun acara sunat Rasul. Melalui tradisi Manoe Pucok manusia diajarkan sopan santun, tatapergaulan dan tatakarma dengan rekan sebaya maupun dengan masyarakat sekitar sertamampu mengenang dan mengingat jasa kasih sayang kedua orang tua yang telah mendidik dan membesarkan sang anak hingga orang tersebut beranjak dewasa. Pengertian makna tradisi Manoe Pucok dalam masyarakat Gampong Gunong Cut merupakan ungkapan yang di simbolkan dalam pembersihan diri sebelum seseorang menempuh kehidupan yang baru serta mengandung unsur nasihat dalam membangun suatu akhlak mulia terhadap orang tua, kerabat sendiri, pasangan hidup maupun dengan masyarakat. Selain itu di dalam upacara Manoe Pucok juga terkandung simbol-simbol yang mempunyai makna tersendiri dan media atau alat komunikasi bagi masyarakat untuk memahami dan mengetahui nilai dan norma yang berlaku dalam masyarakat. Upacara Manoe Pucok dalam masyarakat berperan sebagai sarana pengendalian sosial, kontak sosial, interaksi dan komunikasi antar warga masyarakatnya, sehingga dapat mewujudkan kegotongroyongan, persatuan dan solidaritas diantara sesama warga masyarakat.
\end{abstract}

Kata Kunci: Tradisi, Manoe Pucok, Upacara Perkawinan 


\section{A. Pendahuluan}

Kebudayaan adalah keseluruhan gagasan dan karya manusia, yang harus dibiasakan dengan belajar beserta keseluruhan dari hasil budi karyanya itu. Sesuai dengan pengertian di atas kebudayaan merupakan kebiasaan yang dilakukan oleh sekelompok masyarakat dan memiliki norma-norma yang telah dibenarkan oleh masyarakat tersebut. Menurut Gunawan (2009 : 67) kebudayaan adalah saran hasil karya, rasa dan cipta masyarakat. Dari berbagai pengertian dan kedua definisi tersebut di atas, dapat diperoleh pengertian mengenai kebudayaan dalam dua hal yakni, pertama, kebudayaan yang berupa pengetahuan dan meliputi sistem ide atau gagasan yang terdapat pada pikiran manusia.

M. Jakfar Puteh (2012 : 8) menjelaskan bahwa setiap daerah memiliki kebudayaan yang beraneka ragam, salah satunya yaitu provinsi Aceh. Adapun unsur kebudayaan itu dituangkan dalam bentuk kesenian yaitu baik berupa seni tari dan adat dalam perkawinan. Aceh merupakan daerah yang memilki keanekaragaman budaya tradisi yang berbeda-beda. Aceh Barat Daya merupakan salah satu Kabupaten dalam Provinsi Aceh yang mempunyai beberapa adat. Salah satunya adalah upacara "Manoe Pucok" pada prosesi adat perkawinan.

Manoe Pucok merupakan kisah yang diambil dari cerita tentang legenda Malelang-Madion. Malelang-Madion adalah kisah kehidupan sepasang kekasih yang saling mencintai, namun kisah cinta mereka harus berakhir di usia muda karena hasutan Perdana Menteri yang pernah ditolak pinangannya oleh Madion. Mereka dituduh telah menodai kesucian kerajaan dengan perbuatan zina sehingga dijatuhi hukuman rajam sampai mati oleh pihak kerajaan. Legenda Malelang Madion telah sangat lama berkembang dan mempengaruhi kehidupan masyarakat di pesisir Barat Aceh, khususnya di Aceh Barat Daya (Wahyuni 2012 : 73).

Upacara Manoe Pucok merupakan suatu tradisi di dalam ritual perkawinan di Aceh Barat Daya yang dilakukan sebelum ijab kabul dilakukan. Manoe Pucok merupakan pelengkap upacara pernikahan bagi masyarakat Gunung Cut. Manoe Pucok ini dilakukan sehari sebelum menjelang acara peresmian di kediaman pengantin wanita. Fenomena yang menarik adalah Manoe Pucok ini dilaksanakan oleh seorang Syeh (ketua) wanita yang mengisahkan bagaimana kesedihan orang 
tua, dan kerabat dekat untuk melepaskan dengan sangat berat masa lajang anaknya untuk berhasil mengantarkanya ke jenjang pernikahan. Semua para undangan juga merasakan kesedihan yang dirasakan oleh para keluarga seperti kisah Malelang Madion. Pada prosesi terakhir Manoe Pucok, kedua pengantin dimandikan dengan pucok siur yang sudah dihias sedemikian rupa yang menyerupai janur (boh luluk) dan air mandi yang telah disediakan di dalam bejana-bejana kuningan disebut Peuleman.

Prosesi Manoe Pucok ini dilakukan diiringi dengan tarian yang dilakukan oleh para penari wanita yang berjumlah 8 orang. Gerakan-gerakan tari ini sangat sederhana seperti membentuk lingkaran dan mengelilingi pengantin wanita, dengan gerakan awal dilakukan penghormatan kepada para undangan yang hadir, selanjutnya penari bergerak melingkari mempelai pengantin. Dan pada akhir tarian, penari akan melingkari pengantin sampai para keluarga akan memandikannya. Lantunan syair tron tajak mano yang menggambarkan bagaimana kebiasaan seorang ibu memandikan anaknya, sampai seorang ibu selesai memandikan anaknya. Syeh terus mengisahkan syair-syair kesedihan sampai berakhir dengan kata saleum peuntoh dan seulawet. Selanjutnya pengantin diberi pakaian baru yang disebut seunalem mano yang merupakan pemberian kerabat dari pihak pengantin perempuan yang menandai prosesi telah berakhir, dan keesokan harinya adalah persandingan di pelaminan (duek sandeng).

\section{B. Metode Penelitian}

Dalam penelitian ini penulis menggunakan metode kualitatif, yaitu penelitian dengan mengumpulkan data lapangan yang kemudian dibahas dan dianalisis dengan mengacu pada landasan teoritis. Pendekatan yang penulis lakukan adalah Antropologi Budaya. Antropologi Budaya adalah studi antropologi yang mengkaji tentang seluruh sistem gagasan dan rasa, tindakan serta karya yang dihasilkan manusia dalam kehidupan bermasyarakat, yang dijadikan miliknya dengan belajar serta digunakan untuk menghadapi lingkungan dimana manusia itu hidup.

Informan Kunci yaitu mereka yang mengetahui dan memiliki informasi pokok yang diperlukan dalam penelitian. Informan pokok yaitu ditanyakan kepada 
Tokoh Adat di Gampong Gunong Cut Kecamatan Tangan-tangan Kabupaten Aceh Barat Daya, orang tua yang ada di Gampong, orang yang menikah, wali yang menikahkan serta keluarga yang terkait dengan penelitian. Adapun Informan Penghubung yaitu masyarakat yang terlibat langsung dalam tadisi Manoe Pucok. Informan yang akan ditanyakan adalah Geuchik, Sekretaris Desa, Teungku Imum, Ketua pemuda dan masyarakat sekitar. Dala hal ini mengunakan teknik pengumpulan data dengan melakukan observasi, wawancara, studi literatur dan studi dokumentasi dengan analisis data triangulasi.

\section{Pembahasan}

Makna Perlengkapan dan Prosesi Tradisi Manoe Pucok Menurut Masyarakat Gampong Gunong Cut

Berbicara mengenai kebudayaan dan adat istiadat di Indonesia tidak ada habisnya karena keberagagamannya memiliki nilai yang tak dapat diukur. Adat istiadat tersebut memiliki makna simbolik dari setiap prosesinya. Menurut Kamus Besar Bahasa Indonesia yang dikutip Permata Sari dalam jurnal ilmiah mahasiswa Program Studi Pendidikan Seni Drama, Musik dan Tari, FKIP Unisyiah menyatakan, "Adat itiadat merupakan tata kelakuan yang kekal dan turuntemurun dari generasi ke generasi lain sebagai warisan tata kelakuan sehingga kuat integrasinya dengan pola-pola perilaku masyarakat" (Sari, 2017:69). Misalnya upacara pernikahan yang terus di turunkan kepada generasi ke generasi yang lambat laun menjadi kebiasaan dan kebutuhan, kemudian tak luput menjadi aturan, persyaratan dan sebuah ketentuan.Adat dan kebudayaan masyarakat Aceh yang telah diwarisi secara turun-temurun eksistensinya sangat dijiwai oleh masyarakat yang menjalankannya.

Sari menjelaskan, "Manoe yang artinya mandi dengan membersihkan tubuh dengan mempergunakan air yang disiram ke seluruh tubuh, sedangkan Pucok berarti daun muda, daun yang dimaksud adalah daun kelapa muda. Upacara Manoe Pucok merupakan suatu upacara yang terdapat di acara pernikahan dan khitanan (Sunat Rasul).Pelaksanaan Manoe Pucok di acara pernikahan ini memandikan pengantin sebelum dilepaskan oleh orang tuanya dengan tujuan agar si anak bersih dan suci ketika sudah memasuki kehidupan berumah tangga, bersih 
dan suci ketika masa akil baliq (dewasa).Maka dapat dikatakan makna dari tradisi Manoe Pucok baggi masyarakat Aceh merupakan suatu pengungkapan yang disimbolkan dalam bentuk upacara yaitu pembersihan diri sebelum menempuh kehidupan baru" (Sari, 2017: 71-72).

Tradisi Manoe Pucok merupakan bagian dari serangkaian upacara yang senantiasa dilaksanakan pada resepsi pernikahan yang telah ada sejak jaman nenek moyang. Prosesi tradisi Manoe Pucuk yang dilakukan oleh masyarakat GampongGunong Cut diawali dengan persiapan perlengkapan, persiapan dan prosesi Manoe Pucok yang memiliki makna simbolik yang berbeda dengan etnis lainnya yang ada di daerah Aceh. Manoe Pucok dilaksanakan dengan serangkaian proses seperti persiapan, perlengkapan dan proses berjalannya Manoe Pucok.

a. Persiapan awal

Pelaksanaan prosesi Manoe Pucok dilaksanakan dengan mengundang kelompok ibu Marhaban (berzanzi) dan melaksakan prosesi tepung tawar terhadap kedua mempelai oleh orang tua dan keluarga lainnya.

b. Persiapan Perlengkapan Prosesi Manoe Pucok

1. Kerajinan Nyiu (Janur Putih)

Kerajinan Nyiu (janur putih) ini sudanh menjadi tradisi dalam setiap acara pernikahan. Bahan baku pembuatan janur putih menggunakan daun kelapa (pucuk daun kelapa).Kerajinan tersebut dilakukan oleh ibu-ibu masyarakat gampong. Bentuk motif dari kerajinan bermacam-macam seperti:
a. Lipatan tikar
b. Jari lipan
c. Kris
d. Bunga

2. Air Limau (Ie Limee)

Mempersiapkan air dan air perasan bunga (dalam bahasa Aceh disebut ie lime). Bunga yang dibunakan adalah bunga alami, seperti: bunga Seulanga, mawar, melati, daun pandan wangi, daun nilam dan buah jeruk Purut (Boh Kruet). Makna simbolik dari air limam adalah untuk kesucian yang bermakna untuk mensucikan pengantin laki-laki dan perempuan.Berikut 
adalah dokumentasi dari prosesi membuat air limau yang dilakukan oleh ibu-ibu di gampong.

3. Beras Ketan Putih yang Dicampur Beras Ketan Merah

4. Mempersiapkan racikan yang terdiri dari bunga mawar, bunga kantil, rajangan daun sera, dan pandan dan bak kala.

5. Menyajikan Perlengkapan Tradisi Manoe Pucok

Semua perlengkapan disediakan dalam perlengkapan Peusijuek dan pakaian (Ija Seunalen Manoe) dalam sebuah talam, seperti: Ketan (Bu Lekat), campuran beras ketan putih dan merah, tempat cuci tangan (tembok rah jaroe), dan air limau (ie lime).

Prosesi Manoe Pucok dilaksanakan dengan membaca lantunan ayat suci Alqur"an, yaitu:

- Membaca basmallah

- Membaca shalawat kepada Nabi Muhammad SAW sebanyak 3 kali

- Dan membaca do'a Allahumaj 'alwaladi min ummatihi wa min jafa'atihi birahmatika ya arhamarrahimin. Amin.

Upacara adat tidak terlepas dengan kontekskebudayaan."Kebudayaan mempunyaifungsi yang sangatbesar bagi kehidupan manusia dan masyarakat, Karena setiap manusia dalam masyarakat selalu melakukankebiasaan baik atau buruk bagi dirinya. Kebiasaan yangbaik akan diakui dan dilakukan oleh orang lain, yangkemudian dijadikan sebagai dasar bagi hubungan antaraorang-orang tertentu, sehingga tindakan itu menimbulkannorma-norma yang disebut sebagai adat istiadat" (Adhye,2010 : 25).

Tradisi Manoe Pucokmerupakan tradisi yang sudah lama berkembang di Kabupaten Aceh Barat Daya, dimana tradisi ini sudah dilakukan sebelum terjadinya pemekaran, sebagai budaya dari nenek moyang yang telah diwariskan secara turun-temurun dan selalu berkembang serta dilestarikan dalam masyarakat karena budaya tersebut dianggap sesuai dengan adat dan cukup ampuh dalam pengembangan ajaran Islam maka budaya ini terus dilestarikan.

Pemahaman dari Manoe Pucokmerupakan tradisi yang dilakukan oleh masyarakat yang akan melangsungkan perkawinan yang diaplikasikan dalam bentuk nasehat agar seseorang mampu menjalankan kehidupan dengan baik. Oleh 
karena itu tidak jarang jika tradisi ini selalu dijumpai ketika adanya rumah yang mengadakan acara perkawinan maupun Sunat Rasul, akan tetapi tidak dipungkiri juga bila ada rumah yang tidak menjalani tradisi ini dikarenakan tradisi ini tidak ada paksaan untuk melakukannya, tradisi ini hadir apabila tuan rumah yang mengadakan acara tersebut mempunyai hajat, memiliki keinginan dan mampu dalam materi. Jika tradisi tersebut dilaksanakan, maka pada umumnya dapat mengundang khalayak ramai, sehingga acara perkawinan yang dilakukan mengundang orang yang berdatangan untuk melihat.

Manoe Pucok (mandi pucuk) yang dimaksud disini adalah memandikan seseorang yang merupakan salah satu tradisi adat yang berkembang dan masih dipraktekkan oleh sebagian besar masyarakat di Kabupaten Aceh Barat Daya Kecamatan Tangan-tangan khususnya di Gampong Gunong Cut. Tradisi Manoe Pucok dilakukan kepada calon kedua mempelai sebelum melangsungkan acara akad nikah.Prosesi adat ini lah yang menjadi salah satu tradisi yang diwariskan oleh para nenek moyang zaman dulu sampai sekarang yang juga bermanfaat sebagai salah satu tanda akan meninggalkan masa lajang.Manoe Pucokjuga dilakukan pada acara seseorang yang akan di sunat (khitan) yakni anak laki- laki. Pucok secara harfiah bearti daun yang paling muda atau pucuk daun yang paling atas dari batang pohon kelapa (janur).

Tradisi upacara Manoe Pucok di GampongGunong Cut selalu ditemui di setiap rumah-rumah yang mengadakan acara pesta perkawinan, karena Manoe Pucok dilakukan terhadap orang yang akan membina hubungan rumah tangga, maka untuk memasuki ke dalam keluarga yang baru tersebut perlu kiranya mereka dimandikan dengan tujuan agar dalam keluarga baru tersebut sudah lepas dari tanggung jawab orang tua sehingga selanjutnya tidak mendapat bencana.

Dalam membina kehidupan bermasyarakat yang pluralistik agar terwujudnya suasana kedamaian, ketenteraman dankenyamanan, maka perlu adanya keseimbangan atau kesebandinganyang merupakan standar dan sudah menjadi norma yang dijunjung tinggi dalam membina kehidupan masyarakat.Standar dan norma itu salah satu diantaranya adalah yangdinamakan dengan "adat dan adat istiadat" yang sudah tumuh danberkembang dari abad ke abad yang menjadi modal persatuan dankesatuan bangsa. 
Meskipun adat dan adat istiadat berbeda-bedaantara satu lingkungan masyarakat dengan lingkungan masyarakatlainnya, namun adat dan adat istiadat itu menjadi perekat persatuanmasyarakat dan persatuanbangsa. Tradisi Manoe Pucok yang dilakukan sekarang, tentunya terdapat beberapa tahapan-tahapan dalam pelaksanaannya, dimana tahapan tersebut dilalui sehingga sangat bermanfaat bagi masyarakat sebagai perilaku yang mencerminkan budi pekerti dan akal manusia, dimana masyarakat harus tetap menjaga budaya yang telah berkembang dan senantiasa dilestarikan sampai turun temurun ke anak cucu.

\section{Tradisi Manoe Pucok Dalam Masyarakat Gampong Gunong Cut}

Keberadaan hukum adat di Indonesia sangat berpengaruhbanyak pada kehidupan masyarakat, terutama di Aceh Barat Daya. Setiap individubahkan sering merasakan suatu kebanggaan yang besar akan asalusul daerah kampung halamannya dan dari suku mana ia berasal. Seseorang dapat memegang teguh adat dari sukunya yang sering dijumpai pada hal-hal yang berkaitan dengan perkawinan, karenamengenai hal tersebut pada masing-masing daerahmemiliki cara yang khas dan ada suatu ciri yangmenonjol dari adat istiadat masing-masing.

Tradisi perkawinan di beberapa daerah tentunya berbeda-beda dikarenakan sifat kemasyarakatan, adatistiadat, agama dan kepercayaan masyarakat yang berbeda-beda, hal ini dikarenakan dengan adanya kemajuandan perkembangan jaman.Dengan demikian selain adat perkawinan itu sendiri telah mengalami perkembangan danpergeseran nilai, dewasa ini sangat cenderung bahkan sering terjadi pelaksanaan perkawinan yang mengikuti tradisi.

Perkawinan persekutuan masyarakat Aceh Barat Daya erat sekali kaitannya dengan tradisi, bahkandapat dikatakan bahwa suatu peraturan hukum perkawinan sukaruntuk dipahami tanpa dibarengi pelaksanaan, karena itu segala sesuatu yang berlakusudah barang tentu banyak dipengaruhi oleh tradisi dalam suatu daerah.

Pelaksanaan perkawinan melalui tradisi Manoe Pucok di Gampong Gunong Cut Kecamatan Tangan-tangan Kabupaten Aceh Barat Daya banyak mengandung kegiatan dan memiliki makna penting yang dapat memperkaya khasanah adat istiadat di Aceh Barat Daya umumnya.Selain itu nilai-nilai dan norma adat perkawinan yang telah tertanam di Gampong Gunong Cut mendapat dukungan dalam keberhasilan pembangunan. 
Manoe Pucok merupakan tradisi untuk melepaskan kepergian anak gadis untuk membina bahtera rumah tangga dengan lelaki pilihannya. Memandikan dara baroe juga memiliki filosofi untuk membersihkan „si gadis“ dari gangguan setan sebelum ia dilepaskan dari keluarga kepada suaminya. Apalagi ada prosesi dimana ayah menggendong anak gadisnya untuk terakhir kali yang saat ini jarang sekali ada ayah yang mau menggendong anak gadisnya pada prosesi perkawinan yang sakral tersebut. Sehingga dapat dikatakan banyak perbedaan antara tradisi Manoe Pucok dengan acara perkawinan yang biasa dilakukan.

Tradisi Manoe Pucok yang dijalankan di Gampong Gunong Cut memiliki kearifan lokal yang menjadi modal sosial dalam pelestarian nilai-nilai hukum adat dan penghormatan terhadap warisan budaya leluhur yang memiliki nilai kearifan sebagai modal sosial bagi pembangunan dalam mencapai kesejahteraan. Kearifan lokal merupakan seperangkat modal sosial yang dimiliki suatu masyarakat yang dapat dimanfaatkan untukmenjaga kelestarian nilai-nilai adat dan hukum adat tetap terpeliharasecara alami sebagaimana yang terjadi pada masyarakat Gampong Gunong Cut, Kecamatan Tangan-tangan, Kabupaten Barat Daya adalah sesuatu yang menarik diteliti ditengah kesibukan orang berbicara tentang kehidupan modern.

Tradisi Manoe Pucok merupakan suatu bagian yang sudah melekat dan selalu dilakukan pada acara upacara perkawinan maupun upacara sunat Rasul yang benar-benar sakral dilakukan.Melalui tradisi Manoe Pucok, mengajarkan tentang bagaimana sopan santun, tata pergaulan dengan orang tua maupun sesama rekan sebaya. Serta tata krama untuk mengenang dan mengingat jasa kasih sayang kedua orang tua yang telah mendidik dan membesarkan sang anak hingga beranjak dewasa. Tradisi ini tentunya memiliki fungsi dan makna luas baik itu dalam hal yang sifatnya nyata ataupun hal yang sifatnya tersirat. Tradisi ini tercipta sesuai dengan adat masyarakat Aceh Barat Daya sebagai pengembangan dari ajaran Islam, adat yang ditegakkan di atas agama, mempunyai nilai yang sangat tinggi terutama dalam pemantapan ajaran Islam, oleh sebab itu tradisi Manoe Pucok masih terus dilestarikan oleh masyarakat Gampong Gunong Cut Kecamatan Tangan-tangan Kabupaten Aceh Barat Daya. 


\section{Kesimpulan}

Adapun kesimpulan dari hasil penelitian di atas adalah sebagai berikut :

1. Pemahaman tradisi Manoe Pucok pada masyarakat Gampong Gunong Cut merupakan bagian yang senantiasa dilakukan dalam upacara perkawinan maupun acara sunat Rasul. Melalui tradisi Manoe Pucok manusia diajarkan sopan santun, tata pergaulan dan tata karma dengan rekan sebaya maupun dengan masyarakat sekitar serta mampu mengenang dan mengingat jasa kasih sayang kedua orang tua yang telah mendidik dan membesarkan sang anak hingga orang tersebut beranjak dewasa.

2. Pengertian tradisi Manoe Pucok dalam masyarakat Gampong Gunong Cut merupakan ungkapan yang disimbolkan dalam pembersihan diri sebelum seseorang menempuh kehidupan yang baru serta mengandung unsur nasihat dalam membangun suatu akhlak mulia terhadap orang tua, kerabat sendiri, pasangan hidup maupun dengan masyarakat. Selain itu di dalam upacara Manoe Pucok juga terkandung simbol-simbol yang mempunyai makna tersendiri dan media atau alat komunikasi bagi masyarakat untuk memahami dan mengetahui nilai dan norma yang berlaku dalam masyarakat. Upacara Manoe Pucok dalam masyarakat berperan sebagai sarana pengendalian sosial, kontak sosial, interaksi dan komunikasi antar warga masyarakatnya, sehingga dapat mewujudkan kegotong-royongan, persatuan dan solidaritas diantara sesama warga masyarakat. 


\section{DAFTAR PUSTAKA}

Abdullah, Irwan. 2006. Konstruksi dan Reproduksi Kebudayaan. Yogyakarta : Pustaka Pelajar.

Afrida, 2012. Ritual Masyarakat Aceh Dalam Menyambut Kelahiran Anak. Jurusan Antropologi: Universitas Malikussaleh

Alo Liliweri. 2014. Pengantar Studi Kebudayaan. Bandung : Nusa Media.

Geertz, C. 2003. Ritual and Social Change. American Atropologist.

Gunawan, Samuel. 2009. Antropologi Budaya (Suatu Perspektif Kontemporer). Jakarta : Erlangga.

Hadi, Amirul. 2004. Islam and State in Sumatra. Provinsi Aceh : Balai Kajian Sejarah dan Nilai Tradisional Aceh.

2010. Aceh Sejarah Budaya dan Tradisi. Jakarta : Pustaka Obor Indonesia.

Kawilarang, Harry. 2008. Aceh Dari Sultan Iskandar Muda ke Helsingki. Banda Aceh : Bandar Publishing.

Keesing, Roger M. 1981. Masyarakat Desa Di Indonesia. Jakarta : Fakultas Ekonomi Universitas Indonesia.

Koentjaraningrat. 1999. Pengantar Ilmu Antropologi. Jakarta : PT. Rineka Cipta. 2002. Pengantar Ilmu Antropologi. Jakarta : PT. Rineka Cipta.

Loeb, Edwin. 1989. Sumatra Ist History and People, with additional chapter by Robert Heine Gelden. Singapura : Oxford University Pressd.

M. Jakfar Puteh. 2012. Sistem Sosial Budaya dan Adat Masyarakat Aceh. Yogyakarta : Grafindo Litera Media.

Mattulada. 2007. Kebudayaan Kemanusiaan Dan Lingkungan Hidup. Makasar : Hasanuddin University Press.

Moleong, Lexy. 2010. Metode Penelitian Kualitatif. Bandung : Remaja Rosda Karya.

Permata Sari, 2017. Makna Simbolik Pada Perlengkapan Manoe Pucok Aceh Barat Daya. Banda Aceh: Jurnal Ilmiah Mahasiswa Program Studi Pendidikan Drama, Tari dan Musik Fakultas Keguruan Dan Ilmu Pendidikan Unsyiah, Volume II, Nomor 1: 69-78, Februari 2017

Peursen, C.A. Van. 2008. Strategi Kebudayaan. Yogyakarta : Kanisius. 
Prasetya, Joko Tri, dkk. 2004. Ilmu Budaya Dasar. Jakarta : Rineka Cipta.

RPJMG, 2012. Profil Gampong Gunung Cut, Aceh Barat Daya.

Saifuddin, Achmad Fedyani. 2006. Antropologi Kontemporer Sebagai suatu Pengantar Mengenai Paradigma. Jakarta : Kencana.

Setiadi, Elly M. 2007. Ilmu Sosial dan Budaya Dasar. Sunjata, Wahyudi Pantja. 2013. Upacara Tradisional Jawa. Yogyakarta : PT. Tiara Wacana.

Sidanius, Jim \& Pratto, Felicia. 2010. Social Dominance Theory and the dynamic intergroup relations. Physocology Press.

Sulaeman, 2012. Prosesi Perkawinan Keraton di Kota Cirebon. Universitas Diponegoro, Jawa Barat

Susanto, Astrid S. 2005. Pengantar Sosiologi dan Perubahan Sosial. Yogyakarta : Bina Cipta.

Sztompka, Piotr. 2007. Sosiologi Perubahan Sosial. Jakarta : Prenada Media Grup 